\title{
Emergency pre-hospital management of patients admitted with acute asthma
}

\author{
A J Simpson, S P Matusiewicz, P H Brown, I A McCall, J A Innes, A P Greening, \\ G K Crompton
}

Respiratory Medicine Unit, Western General Hospital, Crewe Road South, Edinburgh EH4 2XU, UK

A J Simpson

S P Matusiewicz

P H Brown

I A McCall

$\mathrm{J}$ A Innes

A P Greening

G K Crompton

Correspondence to: Dr G K Crompton

Received 29 March 1999 Returned to authors 6 July 1999

Revised manuscript received 4 October 1999

Accepted for publication

21 October 1999

\begin{abstract}
Background-Little is known about the management of acute asthma prior to hospital admission. Pre-hospital treatment of patients referred to hospital with acute asthma was therefore studied in $\mathbf{1 5 0}$ patients divided into three groups: those in the Edinburgh Emergency Asthma Admission Service (EEAAS) who can contact an ambulance and present directly to respiratory services when symptoms arise $(\mathrm{n}=38)$, those under continuing supervision at a hospital respiratory outpatient clinic $(n=54)$, and those managed solely in primary care $(n=58)$. Methods-Standardised admission forms detailing aspects of pre-hospital management, case records, GP referral letters, and ambulance patient transport forms were analysed.

Results-In each group airflow obstruction had improved upon arrival at hospital, the effect being most marked in patients transported by ambulance $(p<0.001)$ and in those receiving nebulised $\beta_{2}$ agonists prior to admission $(p<0.005)$. However, $25 \%$ of patients arrived without having nebulised $\beta_{2}$ agonists and 37\% without having glucocorticoids. EEAAS patients were least likely to receive nebulised $\beta_{2}$ agonists before arrival at hospital $(p<0.05)$. This observation was attributable to a tendency for these patients to travel to hospital by car rather than by ambulance.

Conclusions-There is an important shortfall in administration of bronchodilators and glucocorticoids for acute asthma before arrival at hospital. Ambulances equipped with nebulised bronchodilators provide the optimal mode of transport to hospital for patients with acute asthma. In Edinburgh ambulances are not being used by a significant proportion of the population with asthma, possibly because of the mistaken belief that personal transport arrangements reduce journey time to hospital.

(Thorax 2000;55:97-101)
\end{abstract}

Keywords: asthma; pre-hospital treatment; ambulance; $\beta$ agonist
The Edinburgh Emergency Asthma Admission Service (EEAAS) was established in 1968 with the aim of ensuring rapid, efficient access to emergency respiratory services for patients with episodes of life threatening asthma. ${ }^{1}$ Patients are given instructions such that, when distressing symptoms arise, they may present directly to the Respiratory Medicine Unit, an ambulance (equipped with oxygen and nebulised bronchodilators) being arranged directly by them or the ward staff following a telephone call to the unit using a dedicated extension number. Patients are encouraged to take oral glucocorticoids whilst transport is awaited. Upon initiation of the system, physicians await the patient's arrival. The service is thus designed to ensure both prompt presentation to hospital and early administration of glucocorticoids and $\beta_{2}$ agonists in the event of an attack of asthma.

The service has acted as a model for similar services elsewhere and has been shown to be both efficient and effective. ${ }^{2}$ However, relatively little is known about patients' contact with medical services and implementation of treatment for severe acute asthma prior to admission to hospital. The present study compared pre-hospital management in three distinct groups of patients admitted to hospital with acute asthma-those registered with the EEAAS, those under continued supervision at a hospital respiratory medicine outpatient department but not registered with the EEAAS, and those managed solely in the community.

\section{Methods}

PATIENTS

The admitting physician at the adult Respiratory Medicine Unit, Western General Hospital, Edinburgh completed a standardised admission form for patients presenting with acute severe asthma. All forms were completed immediately upon the patient's admission to hospital. The form incorporated specific detailed questions relating to emergency use of treatments leading up to admission, mode of referral, and mode of transport. The diagnosis of acute asthma was confirmed by a consultant respiratory physician in all cases.

The data obtained were stored on a computer database. The first 150 patients registered 
Table 1 Combinations of $\beta_{2}$ agonists and glucocorticoids prescribed as maintenance treatment for patients with asthma

\begin{tabular}{lccc}
\hline & $\begin{array}{l}\text { Primary } \\
\text { care } \\
(n=58)\end{array}$ & $\begin{array}{l}\text { Clinic } \\
(n=54)\end{array}$ & $\begin{array}{l}\text { EEAAS } \\
(n=38)\end{array}$ \\
\hline Nil & 6 & 0 & 0 \\
$\begin{array}{l}\text { BD only } \\
\text { BD + low dose inhaled } \\
\text { glucocorticoid }\end{array}$ & 16 & 0 & 1 \\
$\begin{array}{l}\text { BD + high dose inhaled } \\
\text { glucocorticoid }\end{array}$ & 25 & 16 & 2 \\
$\begin{array}{l}\text { BD, inhaled glucocorticoid } \\
\quad+\text { oral glucocorticoid }\end{array}$ & 0 & 34 & 30 \\
$\begin{array}{l}\text { Low dose inhaled } \\
\text { glucocorticoid only }\end{array}$ & 1 & 4 & 5 \\
\begin{tabular}{l} 
Unknown \\
\hline
\end{tabular} & 2 & 0 & 0 \\
\hline
\end{tabular}

$\mathrm{BD}=$ bronchodilator; low dose inhaled steroid = less than $1 \mathrm{mg}$ of any inhaled corticosteroid in a 24 hour period; high dose inhaled steroid $=$ at least $1 \mathrm{mg}$ of any inhaled corticosteroid in a 24 hour period.

in this way were studied. In the event of a patient having been admitted on more than one occasion, only the first admission was analysed. None of the patients studied required mechanical ventilation or admission to the intensive therapy unit.

All cases were assigned to one of three groups depending on previous asthma management. Thirty eight patients were members of the EEAAS, 54 patients were under continued supervision at the hospital respiratory outpatient department but were not registered with the EEAAS (referred to as "clinic" patients), and the remaining 58 patients had no prior contact with hospital respiratory services, their management being solely co-ordinated by primary care (referred to as "primary care" patients).

Additional data were obtained, where appropriate, from the referring general practitioners' letters and ambulance crew patient transport forms.

The following data were acquired and analysed: pre-existing asthma therapy, modes of referral and transport to hospital, preadmission emergency treatment, and peak expiratory flow (PEF) measured before and upon presentation to hospital.

DATA ANALYSIS

Except where otherwise stated, parameters studied did not conform to a normal distribution and non-parametric statistical analyses were used. For responses generating numerical data the Kruskal-Wallis test was used to test for differences between the three groups. In the event of statistical significance (taken as $\mathrm{p}<0.05)$ the difference between one group and another was analysed using the Mann-Whitney $\mathrm{U}$ test. For paired numerical data (for example, peak expiratory flow before and upon arrival in hospital) the Wilcoxon signed rank test was used. For responses generating nominal data the $\chi^{2}$ test was used.

\section{Results}

DEMOGRAPHIC DATA AND BACKGROUND TO ASTHMA

Clinic patients were significantly older than EEAAS and primary care patients (median ages 42, 35, and 30 years, respectively, $\mathrm{p}<0.01)$. Most patients $(71 \%)$ were female with no significant difference between groups. EEAAS patients had taken more courses of prednisolone in the six months prior to admission than the other two groups with a median of two courses for EEAAS patients, one for clinic patients, and none for primary care patients $(p<0.0001)$.

MAINTENANCE TREATMENT FOR ASTHMA

Treatment with $\beta_{2}$ agonists and glucocorticoids as part of maintenance treatment is shown in table 1 . The average daily dose of inhaled glucocorticoid prescribed was significantly different in the three groups with mean doses of $1760 \mu \mathrm{g}$ for EAASS patients, $1470 \mu \mathrm{g}$ for clinic patients, and $740 \mu \mathrm{g}$ for primary care patients $(p<0.0001)$, though no attempt was made to correct for equivalence of dose for different steroid preparations or inhalation devices. ${ }^{34}$ Thirty five patients were being treated with long acting $\beta_{2}$ agonists (four primary care patients, 15 clinic patients, and 16 EEAAS patients), 19 with oral theophyllines (three primary care, seven clinic patients, and nine EEAAS patients), 20 with anticholinergics (one primary care patient, 13 clinic patients, and six EEAAS patients), 10 with nedocromil or cromoglycate (one primary care patient, five clinic patients, and four EEAAS patients), and one EEAAS patient was being treated with methotrexate.

MODE OF REFERRAL AND TRANSPORT TO HOSPITAL

The median duration of symptoms prior to admission was 14 hours for EEAAS patients, 12 hours for clinic patients, and 10 hours for primary care patients (no significant difference, $p=0.67$ ). Of the EEAAS patients, nine $(24 \%)$ requested a visit from their general practitioner which potentially delayed admission to hospital while the remaining 29 (76\%) presented as self-referrals. Self-referral was used by six primary care patients $(10 \%)$ and five clinic patients (9\%).

Twenty five EEAAS patients (68\%) used transport to hospital with no access to emergency treatment (table 2) and approximately one third of primary care patients and a quarter of clinic patients travelled to hospital by car (table 2 ).

\section{PRE-HOSPITAL TREATMENT}

EEAAS patients were significantly less likely to be treated with a nebulised $\beta_{2}$ agonist prior to admission than were patients in the other groups studied (fig 1 ). Of the 14 EEAAS patients not receiving a nebulised $\beta_{2}$ agonist 12 were self-referrals to hospital, 11 of whom came to hospital by car and one by bus. The remaining two patients were seen by a GP; one

Table 2 Mode of transport used by patients admitted to hospital with acute asthma

\begin{tabular}{llll}
\hline & Primary care & Clinic & EEAAS \\
\hline Ambulance & 36 & 39 & 12 \\
Car & 20 & 13 & 24 \\
Other & 1 & 1 & 1 \\
\hline
\end{tabular}


came to hospital by ambulance and the other by car. Fifty three of 142 patients $(37 \%)$ did not receive oral or intravenous glucocorticoids prior to admission (17/54 primary care patients $(31 \%), 20 / 52$ clinic patients $(37 \%), 16 / 36$ EEAAS patients (44\%); no significant difference, $\mathrm{p}=0.45$; fig 1 ). EEAAS patients were significantly more likely to start a course of oral glucocorticoids of their own volition (11/27 (41\%) EEAAS patients, 6/47 (13\%) clinic patients, and $2 / 51(4 \%)$ primary care patients for whom information was available, $\mathrm{p}<0.0001)$.

MANAGEMENT PROVIDED BY GENERAL

PRACTITIONERS

One hundred and four patients were seen by a general practitioner ( 50 new patients, 45 clinic patients, nine EEAAS patients). In $98 \%$ of cases a letter accompanied the patient and in $91 \%$ of letters a detailed account of patient medication was provided. In $58 \%$ the PEF was recorded.

A $\beta_{2}$ agonist via a nebuliser or large volume spacer device was given by the attending GP in $60 \%$ of cases. Of the remaining patients, $47 \%$ received a $\beta_{2}$ agonist by self-administration or in the ambulance. In all, 20 patients seen by a GP had no record of pre-hospital treatment with a $\beta_{2}$ agonist via a nebuliser or large volume spacer device.

GPs prescribed oral or intravenous glucocorticoids in 67 of 102 cases for whom information was available; intravenous treatment was given to 12 patients. Six were treated with intravenous aminophylline. Antibiotic therapy was prescribed in $21 \%$ of cases.

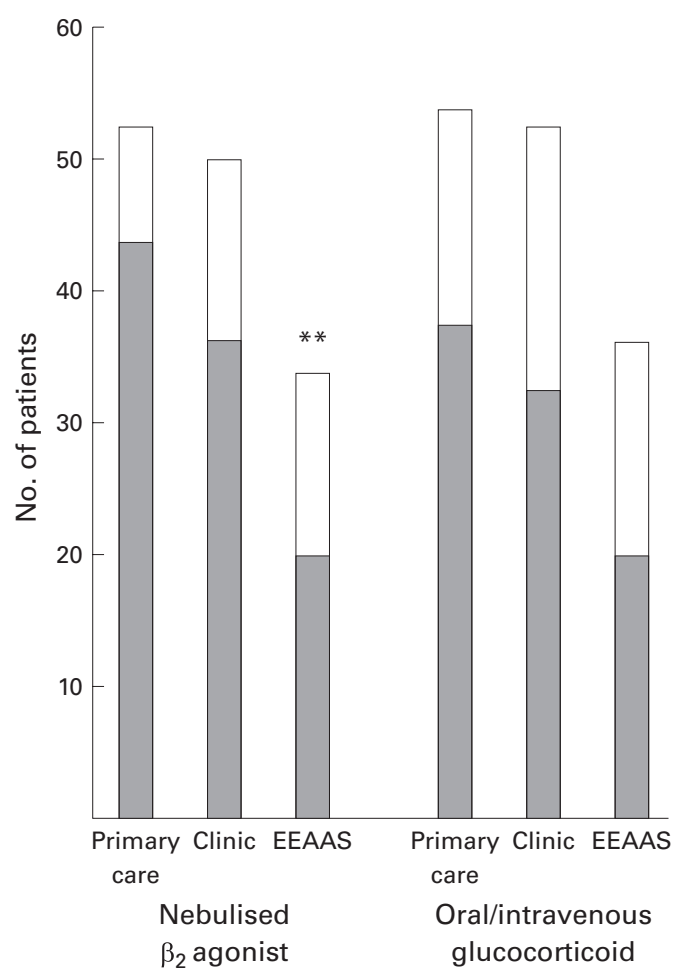

Figure 1 Administration of nebulised $\beta_{2}$ agonists and oral/intravenous glucocorticoids before arrival in hospital. Shaded columns represent patients who received treatment and open columns those who did not. ${ }^{\star \star}$ Lower proportion receiving treatment; $p<0.05$.
Table 3 Peak expiratory flow (PEF) before and on arrival at hospital

\begin{tabular}{llll}
\hline & $\begin{array}{l}\text { PEF prior to } \\
\text { arrival at } \\
\text { hospital (l/min) }\end{array}$ & $\begin{array}{l}\text { PEF on arrival } \\
\text { at hospital } \\
\text { (l/min) }\end{array}$ & p value \\
\hline $\begin{array}{l}\text { All patients }(\mathrm{n}=56) \\
\text { Primary care patients } \\
\quad(\mathrm{n}=25)\end{array}$ & 177.5 & 215.0 & $<0.0001$ \\
$\begin{array}{c}\text { Clinic patients } \\
(\mathrm{n}=26)\end{array}$ & 190.0 & 240.0 & $<0.005$ \\
$\begin{array}{c}\text { EEAAS patients } \\
(\mathrm{n}=5)\end{array}$ & 160.0 & 205.0 & $<0.01$ \\
& 180.0 & 200.0 & $\mathrm{NS}$
\end{tabular}

Data are from patients for whom matched peak expiratory flows (before and on arrival at hospital) were available. Results are presented as medians. Statistical analysis was performed using the Wilcoxon signed rank test; NS = not statistically significant.

MANAGEMENT PROVIDED BY AMBULANCE CREWS

Eighty seven patients were transported to hospital by ambulance. It was recorded that a nebulised $\beta_{2}$ agonist was given by the ambulance crew to 33 of 71 patients $(46 \%)$ and oxygen was given, either alone or to nebulise bronchodilators, in $93 \%$ of cases.

COMPARISON OF PEF BEFORE AND ON ARRIVAL AT HOSPITAL

While the PEF was recorded (by a respiratory nurse) for all patients upon arrival in hospital, only 56 of the patients had PEF recorded (by a GP) prior to arrival in hospital. Thus, 56 patients had PEF recordings before and upon arrival in hospital (25 primary care patients, 26 clinic patients, and five EEAAS patients). In each of these three groups the PEF on arrival at hospital was higher (table 3). Forty four of the 56 patients in whom PEF was recorded before and on arrival in hospital had received nebulised $\beta_{2}$ agonists; in this subgroup the median PEF rose from $170 \mathrm{l} / \mathrm{min}$ to $210 \mathrm{l} / \mathrm{min}$ $(p=0.0032)$. For the 35 patients transported by ambulance for whom PEF was available before and on arrival in hospital, the median $\mathrm{PEF}$ rose from $150 \mathrm{l} / \mathrm{min}$ to $210 \mathrm{l} / \mathrm{min}$ ( $\mathrm{p}=$ $0.0007) ; 11$ of these patients received nebulised $\beta_{2}$ agonists in the ambulance and, in this subgroup, the median PEF rose from $150 \mathrm{l} /$ $\min$ to $220 \mathrm{l} / \mathrm{min}$.

\section{Discussion}

In a small proportion of patients with asthma life threatening airways obstruction develops unpredictably and precipitously. ${ }^{5}$ For these patients delayed specialist treatment is associated with increased morbidity and mortality. ${ }^{5}$ The EEAAS was developed to identify such patients at the time of their first presentation and to provide them with the facility to access emergency respiratory care directly and immediately upon the onset of asthmatic symptoms. The early administration of oral glucocorticoids and bronchodilators is considered to be necessary in acute asthma, ${ }^{5-7}$ and the benefits of nebulised bronchodilators given in ambulances are now well described. ${ }^{8-12}$ In view of this, EEAAS patients are encouraged to self-administer oral glucocorticoids and to contact the Respiratory Medicine Unit early in the course of an attack. The fast track system encourages the use of ambulance transportation to hospital, and all attending ambulances 
are equipped with nebulisers and oxygen to allow $\beta_{2}$ agonists to be given. Potentially, the system offers optimal speed of access to hospital as well as effective first choice treatment for severe asthma prior to arrival, and has provided a widely accepted model for admission of patients with severe asthma.

Despite the potential advantages of the system, the present study has identified a number of shortcomings. Principal among these was the finding that EEAAS patients were significantly less likely than clinic or primary care patients to have nebulised $\beta_{2}$ agonists prior to admission. This was almost entirely attributable to patients self-referring but failing to notify the hospital and travelling by private transport (or public transport in one case) rather than by ambulance. Because use of home nebulised bronchodilators has been associated with delayed presentation and higher mortality, ${ }^{13}{ }^{14}$ EEAAS patients are generally not prescribed nebulisers for domiciliary use. As such, patients not travelling by ambulance are denied nebulised bronchodilators and supplemental oxygen. In this study ambulance transport and use of nebulised $\beta_{2}$ agonists were both associated with highly significant improvements in airflow obstruction upon arrival in hospital.

Why patients should choose to travel to hospital privately rather than by ambulance remains unclear. The EEAAS was established before local ambulances were equipped with nebulisers and the habit of self-transportation may remain instilled in some patients. Alternatively, patients may mistakenly believe that access to treatment is delayed by waiting for an ambulance. Emergency ambulances in Lothian respond to a call, on average, within eight minutes and take an average of 19 minutes to reach hospital ( $\mathrm{R}$ Muirhead, Fife, Lothian and Borders Ambulance Central Control, personal communication).

Over one third of EEAAS patients had not started oral glucocorticoids prior to admission despite previous advice to do so. A further problem identified was that EEAAS patients tended to delay hospital attendance by requesting a GP's visit, despite instructions to present directly in the event of a severe attack. Also, EEAAS patients had symptoms for longer than clinic or primary care patients before seeking medical help, in keeping with findings elsewhere. ${ }^{15}{ }^{16} \mathrm{~A}$ trend therefore appears to exist whereby patients most at risk of severe acute asthma are most susceptible to exhibiting behaviour predisposing to severe attacks. It is interesting to speculate whether this type of behaviour pattern, implying poor compliance or poor response to education, is an important factor in determining why EEAAS patients needed to be enrolled in the service in the first instance. Considerable challenges exist with regard to identifying patients prone to such behaviour and establishing the reasons for it. Furthermore, better strategies are required for conveying useful information to these patients regarding early presentation, self-treatment with glucocorticoids, and transportation to hospital. On the basis of our findings we have re-emphasised to all EEAAS patients the benefits of using ambulance transfer from home to hospital, and have repeated advice about early presentation and self-administration of glucocorticoids. This advice is most intensely targeted at patients who have failed to comply with advice in the course of previous attacks of asthma.

As expected, most clinic and primary care patients were seen by a GP prior to admission to hospital. GPs provided admitting physicians with a great deal of information regarding history, medication, and baseline PEF. As such, GPs complied to a large extent with existing guidelines and generally provided high quality of care, as has been found elsewhere in the setting of acute asthma. ${ }^{17}{ }^{18}$ Largely because of management provided by GPs, clinic and primary care patients had a higher chance than those in the EEAAS group of receiving nebulised $\beta_{2}$ agonists and oral/intravenous glucocorticoids prior to admission. However, a considerable shortfall in provision of optimal pre-hospital emergency treatment was still identified. Most notably, approximately one third of patients seen by a GP were not given nebulised $\beta_{2}$ agonists or glucocorticoids and did not have a PEF recorded, broadly in keeping with findings in comprehensive national surveys. ${ }^{19}{ }^{20}$ Also, antibiotics were frequently prescribed despite lack of evidence for their efficacy in acute asthma. ${ }^{19-22}$ A high proportion of patients seen by GPs travelled to hospital by private transport, suggesting a lack of perception of the benefits of ambulance transport among GPs. The retrospective nature of this study may have led to an underestimation in the reporting of emergency treatments but we consider that any such discrepancy would be small, given both the multiple sources of information available and the fact that all patients had a detailed history taken immediately upon admission to hospital.

Management provided by ambulance crews proved in the main to be of a high standard. Indeed, ambulance transport was associated with the greatest improvement in airflow obstruction for any subgroup analysed. While this may not be directly attributable to treatment administered in the ambulance, it nevertheless strengthens the argument for ambulance transportation. The capacity to improve hypoxaemia using supplemental oxygen in ambulances augments this position. ${ }^{5}$ However, a small proportion of patients who did not receive nebulised $\beta_{2}$ agonists in the ambulance had not received $\beta_{2}$ agonists from a GP or by self-administration. This suggests that an important minority of patients who warrant nebulised $\beta_{2}$ agonists in the ambulance are denied this treatment, a finding that has been described elsewhere, ${ }^{23}$ and which emphasises the need for continued training of ambulance crews with regard to asthma.

This study has identified considerable shortfalls in pre-hospital treatment with $\beta_{2}$ agonists and glucocorticoids as well as delays in accessing hospital. In addition, it has illustrated the practical problems preventing optimal implementation of self-admission services for acute asthma and emphasises the need to review regularly the efficacy of such schemes. 
1 Crompton GK, Grant IWB. Edinburgh Emergency Asthma Admission Service. BMF 1975;4:680-2.

2 Crompton GK, Grant IW, Chapman BJ, et al. Edinburgh Emergency Asthma Admission Service: report on 15 years' experience. Eur f Respir Dis 1987;70:266-71.

3 Wong BJO, Hargreave FE. Bioequivalence of metered-dose inhaled medications. F Allergy Clin Immunol 1993;92: 373-9.

4 Lipworth BJ. Pharmacokinetics of inhaled drugs. Br $\mathcal{F}$ Clin Pharmacol 1996;42:697-705.

5 Harrison BDW. Acute severe asthma. In: Brewis RAL, Gibson GJ, Geddes DM, eds. Respiratory medicine, 1 st ed. London: Baillière Tindall, 1990: 674-90.

6 British Thoracic Society, National Asthma Campaign, British Thoracic Society, National Asthma Campaign,
Royal College of Physicians of London, et al. The British guidelines on asthma managment: 1995 review and guidelines on asthma managment: 1995 review
position statement. Thorax 1997;52 (Suppl 1):S1-21.

7 Cosition statement. Thorax 1997;52 (Suppl 1):S1-21. adults with status asthmaticus. Am $\mathcal{F}$ Respir Crit Care Med 1995;151:1296-316.

8 Wathen CG, Crompton GK, Carrington D, et al. Treatment for acute asthma in the ambulance. Br $\mathcal{F}$ Gen Pract 1990;40: 388.

9 Fergusson RJ, Stewart CM, Wathen CG, et al. Effectiveness of nebulised salbutamol administered in ambulances to patients with severe acute asthma. Thorax 1995;50:81-2.

10 Campbell IA, Colman SB, Mao JH, et al. An open, prospective comparison of $\beta_{2}$ agonists given by nebuliser, tive comparison of $\beta_{2}$ agonists given by nebuliser, emergency treatment. Thorax 1995;50:79-80.

11 Quadrel M, Lavery RF, Jaker M, et al. Prospective, Quadrel M, Lavery RF, Jaker M, et al. Prospective,
randomized trial of epinephrine, metaproterenol, and both in the prehospital treatment of asthma in the adult patient. in the prehospital treatment of as

12 Weiss SJ, Anand P, Ernst AA, et al. Effect of out-of-hospital albuterol inhalation treatments on patient comfort and morbidity. Ann Emerg Med 1994;24:873-8.
13 Windom $\mathrm{HH}$, Burgess CD, Crane J, et al. The selfadministration of inhaled beta agonist drugs during severe acute asthma. NZ Med f 1990;103:205-7.

14 Sears MR, Rea HH, Fenwick J, et al. 75 deaths in asthmatics prescribed home nebulisers. Br Med f Res Educ 1987;294 477-80.

15 Sibbald B. Patient self care in acute asthma. Thorax 1989;44:97-101.

16 Kolbe J, Vamos M, Fergusson W, et al. Differential influences on asthma self-management knowledge and self-management behavior in acute severe asthma. Chest 1996;110:1463-8.

17 Littlejohns P, Hollowell J, Hayward P, et al. Comparison of asthmatic patients admitted to hospital from health districts experiencing high and low asthma mortality rates. Postgrad Med f 1994;70:92-9.

18 North of England Asthma Guideline Development Group. North of England evidence based guidelines development project: summary version of evidence based guideline for the primary care management of asthma in adults. BMF

19 Neville RG, Clark RC, Hoskins G, et al for the General Practitioners in Asthma Group. National asthma attack audit 1991-2. BMF 1993;306:559-62.

20 Neville RG, Hoskins G, Smith B, et al. How general practitioners manage acute asthma attacks. Thorax 1997;52:1536.

21 Graham VAL, Milton AF, Knowles GK, et al. Routine antibiotics in hospital management of acute asthma. Lancet 1982;i:418-20.

22 Teichtahl H, Buckmaster N, Pertnikovs E. The incidence of respiratory tract infection in adults requiring hospitalization for asthma. Chest 1997;112:591-6.

23 Snooks H, Hartley-Sharpe C, Booth H, et al. Audit of care of acute asthma patients by ambulance crews in London. Pre-hosp Immed Care 1999;3:76-80. 